IJBPAS, February, 2022, 11(2): 448-458

ISSN: 2277-4998

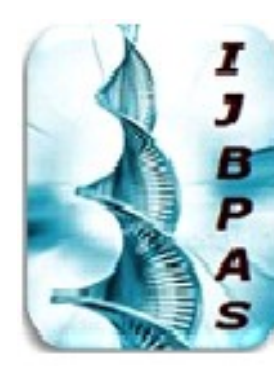

International Journal of Bhology, Pharmacy and Allied Sciences (IJBPAS)

'A B Bridge Betusen Caboratory and QRader'

www.ibpas.com

\title{
EMERGING CONTAMINANTS IN WATER AND THEIR REMOVAL TECHNOLOGIES
}

\author{
BEAUTY $\mathbf{R}^{1}$ AND ANUPAMA $\mathrm{S}^{2 *}$ \\ 1: PG Scholar, Parul Institute of Applied Sciences, Waghodia, Vadodara, \\ Gujarat 391760 \\ 2: Professor, Department of Microbiology, Parul Institute of Applied Sciences, Waghodia, \\ Vadodara, Gujarat 391760 \\ *Corresponding Author: Dr. Anupama S: E Mail Id: anupamashivastav@gmail.com; \\ Tel: +917226094433 \\ Received 13 ${ }^{\text {th }}$ April 2021; Revised $11^{\text {th }}$ May 2021; Accepted $19^{\text {th }}$ June 2021; Available online $1^{\text {st }}$ Feb. 2022 \\ https://doi.org/10.31032/IJBPAS/2022/11.2.5851
}

\begin{abstract}
The event of developing or recently recognized contaminants in our water assets is of proceeded concern for the wellbeing and security of expending open. The existing customary water treatment plants were not planned for these unidentified contaminants. The emerging contaminants contain pharmaceuticals, personal care items, surfactants, different mechanical added substances and various chemicals implied to be endocrine disrupter. These have gotten to be a risk to our water supply arrange. The current wastewater treatment framework isn't effective in disposal of these diverse classes of developing contaminants as these have not been observed due to the absence of exacting control particular to these contaminants. These undesirable compounds are being released, knowingly or unknowingly into the oceanic environment that influence the complete living being. This paper centers on the sort of Emerging Contaminants being evacuated, the conditions of the method and the results accomplished. The most trends in the field are moreover highlighted at the side discerning comments and proposals for encourage developments as well as the distinguishing proof of the current information crevices and future
\end{abstract}


inquire about bearings related to the application of these advances for water treatment and reclamation.

Keywords: emerging contaminants, treatment technologies, phase-changing methods, biological methods, advanced oxidation method

\section{INTRODUCTION}

Examinations of water quality commonly center on supplements, microbial pollutants, metals, and major poisons. The recent research uncovers the presence of a huge number of natural contaminants that essentially influence water quality.These contaminants begin from assorted sources and regularly in concentrations that extend from ng $\mathrm{L}-1$ to $\mu \mathrm{g} \mathrm{L}-1$ [1]. This gather of contaminants, named as developing contaminants (Emerging Contaminants), are chemical compounds that are commonly display in water, are being recognized as critical water poisons. Rising contaminantsare characteristic or artificially happening substances not commonly observed within the environment and having known or suspected undesirable impacts on people and the environment. Unfortunately, the assortment of Emerging Contaminants in water has expanded over the past a long time, primarily as a result of progresses in expository procedures, coming about in its location at very low concentrations in water tests. In spite of the fact that in-depth coherent examinations of poisons such as supplements, hydrocarbons, and overpowering metals in stormwater and wastewater have been endeavoured. Consequently, possible reuse of water damaged with Emerging Contaminants is an ongoing challenge.

\section{Emerging Contaminates in water:} Pharmaceuticals, Antibiotics, biocides, pesticides and personal care products

With progressions within the chemical industry, the assortment of compounds being discharged to the environment which are possibly destructive to people and environment over the long-term is anticipated to develop essentially over a long time. Pharmaceuticals are the dangerous cluster of Emerging Contaminants and their existence in drinking water has created critical concerns with respect to the risk of estrogenic and other unfavourable impacts on people and fauna. The major concerns in connection to anti-biotics, biocides, and pesticides, is the advancement of bacterial resistance after their discharge into the environment and the negative impact on the biodegradation of plant materials, which 
disturbs the essential nourishment chain in aquatic environments. The term 'pesticide' alludes to chemicals used for agrarian purposes, though the term 'biocide' alludes to chemicals used in urban situations [2]. These chemicals are found broadly in urban situations and include fragrances, sunscreens, creepy crawly repellents, and antifungal agents [1]. As these compounds are decided for exterior utilization, no metabolic changes happen in their chemical structure and are easily discharged into oceanic circumstances.

\section{Treatment technologies}

Non-conventional water treatment advances have changed over time as a result of modern strategies being created. These treatments can be mostly partitioned into phasechanging innovations, biological treatment, and progressed oxidation forms. This paper assesses the treatment forms most frequently detailed and their execution characteristics. For this work, ejection efficiencies were taken straight forwardly from the writing without any boost modification.

\subsection{Adsorption using activated carbon (AC)}

Activated carbon (AC) is the foremost habitually utilized fabric because of its large porosity and particular surface zone [3, 4]. These features make AC exceedingly adsorptive and compelling in expelling a range of contaminants. An illustration of AC selectivity is the case of ciprofloxacin. In comparison, a few other contaminants tested has expulsion rates as large as $90 \%$, but as it were after a significantly longer period of time.Large tetracycline removal $(>90 \%)$ were found for the previous two whereas the $\mathrm{AC}$ from activated wood was able to expel $75 \%$ and, coconut shell as it were produced $30 \%$ expulsion [5]. The reason for the contrasts among the types of sources is ascribed to the carbon structure of the crude material, with compacted strands in coconut shell creating minute pore sizes and the nonattendance of extra actuation avoids the generation of modern pores and/or unclogging and extending of existing pores. The evacuation efficiencies run from Sigma [6]. Too interestingly, AC starting from waste sources has been detailed with noteworthy execution within the expulsion of a few particular Emerging Contaminants such as Paracetamol, anti-microbials, and anti-inflammatory drugs [7].

\subsubsection{Adsorption using biochar}

Biochar could be a charcoal-based fabric commonly utilized as a soil amendment. Like most carbon-based materials, biochar is made from heating biomass at large temperature within the nonattendance of oxygen, which is a method known as pyrolysis [8, 9]. Later on 
biochar has been explored for the adsorption of Emerging Contaminants. Pyrolysis conditions is one of the fundamental characteristics of biochar generation prepare influencing its capability for Emerging Contaminants adsorption and treatment productivity [10, 11]. Utilizing the same experimental conditions, biochar without warm actuation was able to achieve $35 \%$ evacuation, whereas utilizing warm enactment the maximum removal accomplished was $<16 \%$ [11]. Utilizing rice husk and rice straw as the feedstock, sulfamethoxazole evacuation was equally $11.6 \%$ but when using soluble base treated rice husk feedstock where nearly $30 \%$ removal was accomplished [12]. The carbon, nitrogen and phosphorus substance in the feedstock has been found to make noteworthy contrasts in the treatment performance of biochar. In any case, the investigation undertaken by author Jeong [13] found that in spite of utilizing biochar from different feedstock materials and different warm treatment conditions for the expulsion of tylosin, the evacuation rate was within the extend of $10 \%$ for all the products. In any case, as biochar has different selectivity, it may be more proficient within the evacuation of a few Emerging Contaminants compared AC [10].

\subsubsection{Adsorption in carbon nanotubes}

Carbon nanotubes (CNTs) are a carbon allotrope with a graphite-like structure and shows diverse adsorption characteristics depending on the degree of twist, the era of the original sheet, distance across, inside geometry, physical-chemical properties and the treatment prepare utilized for union. More often, CNTs are characterized as single-walled nanotubes (SWNT), which have an internal diameter of around $1 \mathrm{~nm}[\mathbf{1 4}$, 15] and multi-walled nanotubes (MWNT), which comprise of a few concentric tubes or laminated graphene layers $[\mathbf{1 5}, \mathbf{1 6}]$. CNTs have been utilized for the expulsion of Emerging Contaminants from water. Surface extend plays a critical part inside the execution of CNTs for ousting Emerging Contaminants. MWNT worked too decently well within the removal of other Emerging Contaminants such as amoxicillin (>90\%), ciprofloxacin $\quad(6.7 \% \quad[\mathbf{1 0}]), \quad$ and ibuprofen/triclosan $\quad(100 \% \quad$ [15] $)$. Additionally, $100 \%$ removal of norfloxacin was accomplished utilizing single-walled CNTs [17], whereas as $35 \%$ evacuation was accomplished utilizing of multi-walled CNTs.Multi-walled CNTs can be arranged from single-walled CNTs by utilizing extra chemical forms [18] to extend the contact zone by a few times and the sum of dynamic 
destinations for adsorption and improving contaminant expulsion effectiveness.

\subsubsection{Adsorption by clay minerals}

The characteristics of the adsorbent fabric directs the productivity of the removal process. The same sort of clay may deliver distinctive evacuation efficiencies depending on the particular sum of nitrogen, press or other minerals display. This is often apparent from the thinks about undertaken by author $\mathrm{Wu} \mathrm{Q}[\mathbf{1 9}]$ and $\mathrm{Wu}$ [20], for the evacuation of ciprofloxacin utilizing montmorillonite (MMT) which brought about in 100\% and $35 \%$ expulsion, individually. This distinction in treatment performance is ascribed to the source of the clay fabric. For the former, the montmorillonite was gotten from the Source of Clays Repository of the Clay Mineral Society in Wyoming which had a cation exchange capacity (CEC) esteem of $85 \mathrm{meq}$ $100 \mathrm{~g}-1$ and particular surface area(SSA) of $23 \mathrm{~m} 2 \mathrm{~g}-1$, individually [24]. Within the case of the latter, the source was a provider in China (San Ding Corp., Zhengjiang) and the CEC and SSA values were $1.1 \mathrm{mmol} \mathrm{g-1} \mathrm{and}$ $35 \mathrm{~m} 2 \mathrm{~g}-1$ [20]. However, the SSA or CEC values can be adjusted by impregnating with different particles to upgrade treatment execution and selectivity [21, 22]. The permeable lattice can have sizes extending from 1.49 to $3.2 \mathrm{~nm}$, which gives satisfactory space inside the clay mineral to attempt catalysis [23]. Pillared clays have received impressive consideration in later a long time as they give the opportunity for utilizing semiconductors for the debasement of contaminants and to extend the movement of the metal oxide by upgrading the active surface zone.

\subsubsection{Membrane technology}

Membrane methods are another sort of stage changing processes with assortment of applications in Emerging Contaminants evacuation. Membrane are formed from distinctive materials, which provide growth to particular filtering features (e.g., pore measure, surface charge, and hydrophobicity) that determine the contaminant sort that can be held. Membrane processes are based on the utilize of hydrostatic weight to remove suspended solids and large atomic weight solutes and permit water and moo atomic weight solutes to pass through. Membrane filtration can be classified as: ultrafiltration (UF), nanofiltration (NF), microfiltration (MF), forward osmosis (FO), and turn around osmosis (RO).Microfiltration is broadly utilized since it can be embraced at atmospheric pressure. In spite of a few points of interest, MF cannot remove contaminants of estimate $<1 \mu \mathrm{m}$ (i.e., broken up solids) and it isn't useful for the evacuation of Emerging 
Contaminants $[24,25]$. The previous was able to achieve $75 \%$ evacuation, while the last mentioned was able to dispense with up to $98 \%$ of the stack within the test influent [26, 27]. Similarly, author Melo-Guimaraes [27] utilized two diverse phthalate corrosive derivatives (Bis-2-ethylhexylphthalate and butylbenzylphthalate) with the same sort of UF layer (Polyvinylidene fluoride-made; 100 $\mathrm{kDa}$ pore estimate from ABSCOR-Koch Frameworks), accomplishing 15\% and 78\% evacuation, separately. For the most part, polar, profoundly water dissolvable Emerging Contaminants are effectively expelled by UF compared to non-polar, low water soluble compounds. Moreover, NF membrane forms work at a low feed water pressure, which suggests a critical advantage in case the operation cost ought to be considered. NF has been illustrated with higher efficiency than UF within the expulsion of a few Emerging Contaminants.

\subsection{Biological processes}

A few diverse natural forms are accessible, with activated sludge frameworks being commonly utilized to treat Emerging Contaminants since of its effectiveness. Either high-impact or anaerobic forms can be applied depending on the sort of contaminant, as a rule successively coupled with other tertiary treatment forms. As apparent, in spite of actuated slime being the foremost common, other biological frameworks (e.g., soil filtration or organic filtration) have been tried for the expulsion of Emerging Contaminants with curiously comes about. The success of the application of high-impact or anaerobic conditions is related to the transcendent terminal electron-accepting conditions. Author Liu [28] proposed that depending on these characteristics, benzotriazoles seems to be superior expelled beneath high-impact conditions when natural attenuation components drive the biodegradation prepare. This knowledge gap makes opportunity for assist investigate related to the advancement of extraction strategies for the separation and quantification of Emerging Contaminants in enacted slime and/or other biological process by-products. Investigate exploring diverse organic treatment forms including conventional enacted slime, natural supplement evacuation and membrane bioreactors have detailed that as it were effectively biodegradable Emerging Contaminants (e.g., caffeine, diclofenac, trimethoprim) can be removed, whereas moo biodegradables (e.g., sulpiride, metoprolol, bezafibrate) may not be killed at all by natural processes. Depending on the particular compound and the treatment 
conditions (e.g., aerobic or anaerobic), evacuation effectiveness values extend from no removal to about total removal. The characteristics of wastewater from the diverse geological areas change, depending on the significant anthropogenic activities, pre-treatment processes undertaken, and the method plan applied.

\subsection{Advanced oxidation processes}

Intrigued in progressed oxidation forms (AOPs) has expanded in recent a long time related to their capability within the evacuation of pollutants, compared with customary water treatment forms. The great removal rates have been related with the generation of hydroxyl radicals (oxidation potential, $2.8 \mathrm{~V}$ ), the most characteristic of the AOPs. The forms included within the AOPs bunch have distinctive courses of free radical generation and particular work conditions, and may involve different materials. Although the most highlight of AOPs is the generation of hydroxyl radicals, the sort of response for hydroxyl radical generation and the test conditions are exceedingly significant. Within the case of the sono-chemical process, it has been proposed that the coordinate era of hydroxyl radicals from water particles without the usage of intermediate species being competent of completely corrupting a few contaminants [29]. The combination of radiation with the Fenton reagents is comparative to two independent medicines, within the best case driving to slight oxacillin degradation (e.g., 10-15\%). The usage of the Fenton response produced a critical generally debasement accomplishing as large as 90\% and the photo-assisted Fenton process was able to mostly degrade oxacillin within the response

\section{CONCLUSIONS}

As highlighted within the assessment commenced in current year noteworthy research has been commenced for the advancement of innovations for the expulsion of rising toxins (ECs) in water. Noteworthy knowledge gap still exist, which highlights the continuous challenge to assured the security of reused water for human utilization. The key discoveries of this survey are:

- Exploitation of Emerging Contaminants utilizing a single treatment advancement is likely not the most excellent approach for the removal of Emerging Contaminants in water. It is vital to look at the usage of coupled systems which can bridge the insufficiencies in a single innovation for the removal of these complex contaminants appear inside the water environment. 
- Scaling-up studies for natural forms don't recognize the microorganisms used for Emerging Contaminants removals, but only state their usage as activated slime able of eliminating contaminants. Additionally, though this sort of forms has been displayed as a proficient treatment, scaling-up studies don't incorporate exploratory development or point by point characterization of the various forms tried.

- Progressed oxidation forms are displayed in research literature as efficient within the debasement of Emerging Contaminants.

\section{REFERENCES}

[1] Fry JP, Love DC, MacDonald GK, West PC, Engstrom PM, Nachman KE, Lawrence RS. Environmental health impacts of feeding crops to farmed fish. Environment International. 2016 May 1; 91: 201-14.

[2] Margot J, Rossi L, Barry DA, Holliger C. Wiley Interdiscip. Rev.: Water. 2015; 2(5): 457-87.

[3] Ocampo-Prez R. Pharmaceuticals as emerging contaminants and their removal from water. A review. Chemosphere. 2013; 93(7): 126887.
[4] Sotelo JL, Rodríguez AR, Mateos MM, Hernández SD, Torrellas SA, Rodríguez JG. Adsorption of pharmaceutical compounds and an endocrine disruptor from aqueous solutions by carbon materials. Journal of Environmental Science and Health, Part B. 2012 Aug 1; 47(7): 640-52.

[5] Torres-Pérez J, Gérente C, Andrès Y. Sustainable activated carbons from agricultural residues dedicated to antibiotic removal by adsorption. Chinese Journal of Chemical Engineering. 2012 Jun 1; 20(3): 5249.

[6] Robles-Molina J, Lara-Ortega FJ, Gilbert-López B, García-Reyes JF, Molina-Díaz A. Multi-residue method for the determination of over 400 priority and emerging pollutants in water and wastewater by solid-phase extraction and liquid chromatographytime-of-flight mass spectrometry. Journal of Chromatography A. 2014 Jul 11; 1350: 30-43.

[7] Bueno MM, Gomez MJ, Herrera S, Hernando MD, Agüera A, FernándezAlba AR. Occurrence and persistence of organic emerging contaminants and priority pollutants in five sewage treatment plants of Spain: two years 
pilot survey monitoring. Environmental Pollution. 2012 May 1; 164: 267-73.

[8] Ahmad M, Lee SS, Dou X, Mohan D, Sung JK, Yang JE, Ok YS. Effects of pyrolysis temperature on soybean stover-and peanut shell-derived biochar properties and TCE adsorption in water. Bioresource technology. 2012 Aug 1; 118: 536-44.

[9] Vickers NJ. Animal communication: when i'm calling you, will you answer too?. Current biology. 2017 Jul 24; 27(14): R713-5.

[10] Mitchell SM, Subbiah M, Ullman JL, Frear C, Call DR. Evaluation of 27 different biochars for potential sequestration of antibiotic residues in food animal production environments. Journal of Environmental Chemical Engineering. 2015 Mar 1; 3(1): 162-9.

[11] Zheng H, Wang Z, Zhao J, Herbert S, Xing B. Sorption of antibiotic sulfamethoxazole varies with biochars produced at different temperatures. Environmental Pollution. 2013 Oct 1; 181: 60-7.

[12] Liu P, Liu WJ, Jiang H, Chen JJ, Li WW, Yu HQ. Modification of biochar derived from fast pyrolysis of biomass and its application in removal of tetracycline from aqueous solution. Bioresource technology. 2012 Oct 1; 121: 23540.

[13] Jeong CY, Wang JJ, Dodla SK, Eberhardt TL, Groom L. Effect of biochar amendment on tylosin adsorption-desorption and transport in two different soils. Journal of environmental quality. 2012 Jul; 41(4): 1185-92.

[14] Lara IV, Zanella I, Fagan SB. Functionalization of carbon nanotube by carboxyl group under radial deformation. Chemical Physics. 2014 Jan 15; 428: 117-20.

[15] Ren X, Chen C, Nagatsu M, Wang X. Carbon nanotubes as adsorbents in environmental pollution management: a review. Chemical Engineering Journal. 2011 Jun 1; 170(2-3): 395-410.

[16] Kim H, Hwang YS, Sharma VK. Adsorption of antibiotics and iopromide onto single-walled and multi-walled carbon nanotubes. Chemical engineering journal. 2014 Nov 1; 255: 23-7.

[17] Peng H, Pan B, Wu M, Liu Y, Zhang D, Xing B. Adsorption of ofloxacin and norfloxacin on carbon 
nanotubes: hydrophobicity and structure controlled process. Journal of hazardous materials. 2012 Sep 30; 233: 89-96.

[18] Cho HH, Huang H, Schwab K. Effects of solution chemistry on the adsorption of ibuprofen and triclosan onto carbon nanotubes. Langmuir. 2011 Nov 1; 27(21): 12960-7.

[19] Wu Q, Li Z, Hong H. Influence of types and charges of exchangeable cations on ciprofloxacin sorption by montmorillonite. Journal of Wuhan University of Technology-Mater. Sci. Ed. 2012 Jun; 27(3): 516-22.

[20] Wu Q, Li Z, Hong H. Influence of types and charges of exchangeable cations on ciprofloxacin sorption by montmorillonite. Journal of Wuhan University of Technology-Mater. Sci. Ed. 2012 Jun; 27(3): 516-22.

[21] Parolo ME, Avena MJ, Pettinari GR, Baschini MT. Influence of $\mathrm{Ca} 2+$ on tetracycline adsorption on montmorillonite. Journal of colloid and interface science. 2012 Feb 15; 368(1): 420-6.

[22] Yuan S, Long H, Xie W, Liao P, Tong M. Electrokinetic transport of CMC-stabilized $\mathrm{Pd} / \mathrm{Fe}$ nanoparticles for the remediation of PCPcontaminated soil. Geoderma. 2012 Sep 1; 185: 18-25.

[23] Tireli AA, do RosárioGuimarães I, de Souza Terra JC, da Silva RR, Guerreiro MC. Fenton-like processes and adsorption using iron oxide-pillared clay with magnetic properties for organic compound mitigation. Environmental Science and Pollution Research. 2015 Jan; 22(2): 870-81.

[24] Zhou JE, Chang Q, Wang Y, Wang J, Meng G. Separation of stable oilwater emulsion by the hydrophilic nano-sized $\mathrm{ZrO}_{2}$ modified $\mathrm{Al}_{2} \mathrm{O}_{3}$ microfiltration membrane. Separation and Purification Technology. 2010 Nov 20; 75(3): 243-8.

[25] Lu NC, Liu JC. Removal of phosphate and fluoride from wastewater by a hybrid precipitation microfiltration process. Separation and Purification Technology. 2010 Sep 6; 74(3): 329-35.

[26] Franta AK, Lenters TR, Mounce D, Neradilek B, Matsen III FA. The complex characteristics of 282 unsatisfactory shoulder arthroplasties. Journal of shoulder and 
elbow surgery. 2007 Sep 1; 16(5): $555-62$.

[27] Melo-Guimarães A, Torner-Morales FJ, Durán-Álvarez JC, JiménezCisneros BE. Removal and fate of emerging contaminants combining biological, flocculation and membrane treatments. Water science and technology. 2013 Feb; 67(4): 877-85.

[28] Liu YS, Ying GG, Shareef A, Kookana RS. Biodegradation of three selected benzotriazoles under aerobic and anaerobic conditions.
Water Research. 2011. Oct 15; 45(16): 5005-14.

[29] Villegas-Guzman P, Silva-Agredo J, González-Gómez D, GiraldoAguirre AL, Flórez-Acosta O, Torres-Palma RA. Evaluation of water matrix effects, experimental parameters, and the degradation pathway during the $\mathrm{TiO} 2$ photocatalytical treatment of the antibiotic dicloxacillin. Journal of Environmental Science and Health, Part A. 2015 Jan 2; 50(1): 40-8. 